\title{
EVALUASI PENGUKURAN SUMBER DAYA MANUSIA IT TERHADAP PENGELOLAAN IRAISE BEDASARKAN COBIT 5
}

\author{
Megawati ${ }^{1}$, Endang Setianigsih ${ }^{2}$ \\ ${ }^{1}$ Sains dan Teknologi, Sistem Informasi, UIN Suska Riau, Pekanbaru, Indonesia \\ Email: ${ }^{1}$ megawati@uin-suska.ac.id, ${ }^{2}$ endang.setiaa14@gmail.com
}

\begin{abstract}
ABSTRAK
Pusat Teknologi Informasi dan Pangkalan Data (PTIPD) merupakan pusat pengembangan dan pelayanan teknologi informasi. Fungsi (PTIPD) sangatlah penting peningkatan kualitas layanan internet untuk semua civitas akademik UIN Suska Riau. Menyediakan server untuk pengelolaan data terintegrasi bagi aplikasi yang ada di lingkungan UIN Suska Riau. Permasalahan yang didapat saat ini, dengan kurang efektifnya proses pelayanan keluhan pada IRAISE yang dilaksanakan oleh Administrator Customer Care Center, yaitu Administrator kesulitan dalam menangani keluhan yang masuk dan pemberitahuan apakah pelayanan sudah berhasil, pada bulan maret 2019 di PTIPD mengalami mutasi pegawai, sehingga pegawai baru menyesuaikan tugas di tempat yang baru, dan mengalami kekurangan SDM IT pada aplikasi iraise, sehingga banyak keluhan mahasiswa dan laporan keluhan dari Administrator C3 penyelesaiannya ditujukan satu pegawai senior saja, mengakibatkan banyak memakan waktu. Tujuan penelitian ini adalah untuk mengukur tingkat kapabilitas dan Memberikan rekomendasi perbaikan terkait manajemen SDM IT agar kinerja sistem saat ini berjalan lebih baik. Metode yang digunakan adalah Cobit 5 terfokus pada proses APO 07, Pada proses ini melakukan pendekatan terstruktur untuk memastikan struktur yang optimal, penempatan, hak keputusan dan keterampilan SDM. Hasil penelitian ini ialah PTIPD berada pada level 3 yaitu Largely archived (L) bahwa proses yang dilakukan sebelumnya telah dikelola (direncanakan, dipantau dan disesuaikan).
\end{abstract}

Kata Kunci: APO07, Capability Level, Cobit 5, Iraise, SDM IT,

\begin{abstract}
The Information Technology Center and Data Base (PTIPD) is a center for information technology development and services. The function (PTIPD) is very important to improve the quality of internet services for all academic community. Providing a server for integrated data management for applications in Uin Suska Riau. The current problem is, with the ineffectiveness of the complaint service process at Iraise which is carried out by the C3 Administrator, namely the Administrator having difficulty in receiving complaints and notifying whether the service has been successful, in March 2019 at PTIPD experienced employee mutations, so that new employees adjust assignments in a new place, and experiencing a lack of IT human resources in the application, so that many student complaints and complaint reports from C3 Administrators are resolved by leaving only one senior employee, resulting in a lot of time. The purpose of this study is to measure the level of capability and provide suggestions for improvement of IT management so that the current system performance is running better. The method used is Cobit 5, which focuses on the APO 07 process. This process takes a structured approach to ensure optimal structure, placement, decision rights and skills. The result of this research is that PTIPD is at level 3, namely Largely archived $(L)$ that the process carried out before has been managed (planned, monitored and invincible).
\end{abstract}

Keywords: APO 07, Capability Level, Cobit 5, Iraise, SDM IT 


\section{PENDAHULUAN}

Peranan TI tentu harus diimbangi dengan pengaturan dan pengelolaan yang tepat, sehingga kerugian yang mungkin terjadi dapat dihindari agar tepat dalam mencapai tujuan dari organisasi tersebut. TI yang tidak diimbangi dengan pengambilan nilai yang sesuai, hal tersebut tentunya sangat mempengaruhi pengambilan keputusan, termasuk mempengaruhi efektifitas dan efisiensi di dalam tujuan dan strategi organisasi. Dalam Mencapai visi dan misi, suatu instansi tidak bisa bekerja sendiri, tetapi perlu didukung oleh beberapa indikator yang akan menentukan keberhasilannya dalam meraih visi dan misi tersebut. Untuk menerapkan pengelolaan teknologi informasi yang baik, diperlukan suatu kerangka kerja yang dapat membantu dalam pelaksanaan pengelolaan TI tersebut. Adapun kerangka kerja yang digunakan dalam penelitian ini adalah Framework COBIT 5[1].

Pusat komputer UIN SUSKA Riau bertujuan untuk menjadi pusat pengembangan dan pelayanan teknologi informasi untuk seluruh civitas akademika UIN Suska Riau. Pusat Teknologi Informasi dan Pangkalan Data (PTIPD) menetapkan suatu acuan untuk mewujudkan layanan teknologi informasi dalam bentuk standar operasional prosedur (SOP) dalam layanan yang ada, baik layanan akademik maupun non akademik. Dalam menjalankan tugasnya, PTIPD telah memanfaatkan aplikasi IRAISE[2].

Integrated Academic Information System (IRAISE), merupakan sebuah sistem informasi yang berfungsi sebagai integrator informasi akademik yang ada di UIN Suska Riau berbagai unit akademik (program studi / fakultas) sekaligus sebagai sarana komunikasi antar aktifitas akademik kampus. Sistem ini dibangun dari kondisi eksistensi informasi akademik di kampus yang sangat beragam, sehingga membutuhkan sebuah "portal" yang akan mengintegrasikan informasi-informasi tersebut sehingga mempermudah akses public[6].

Berdasarkan hasil observasi dan wawancara yang dilakukan pada pihak pusat bisnis dan beberapa terdapat beberapa permasalahan diantaranya sebagai berikut.

1. Administrator masih kesulitan dalam menangani keluhan yang masuk dan pemberitahuan apakah pelayanan yang dilakukan sudah berhasil

2. pada bulan Maret 2019 di PTIPD mengalami mutasi pegawai, sehingga pegawai baru harus menyesuaikan tugas di tempat yang baru, dan PTIPD mengalami kekurangan SDM IT pada aplikasi iraise, sehingga banyak keluhan mahasiswa dan laporan keluhan dari Administrator Customer Care Center penyelesaiannya ditujukan pada satu individu pegawai senior saja, sehingga mengakibatkan banyak memakan waktu dan tidak efektif.

Berdasarkan penelitian dan permasalah yang sudah didapat, aktifitas pegawai, evaluasi, dan training belum berjalan sesuai dengan standar. Kurangnya pengetahuan pegawai baru terhadap permasalahan yang sering terjadi pada pengelolaan perangkat pada IRAISE pusat komputer UIN Suska Riau dengan menggunakan COBIT 5 APO 07 (Manage IT Human Resources). Tujuan dari penelitian ini adalah untuk mengukur tingkat kapabilitas pengelolaan sehingga dapat mengetahui tingkatan kapabilitas tata kelola TI pada aspek Manajemen SDM TI di masing-masing proses COBIT 5 yang dipilih[7].

\section{Prosedur Evaluasi}

\section{LANDASAN TEORI}

Suatu evaluasi yang dapat mencapai standar di atas adalah evaluasi yang sifatnya ideal, artinya tidak mudah untuk dilaksanakan. Standar yang digunakan untuk melakukan evaluasi mungkin tidak sepenting konsekuensinya, yaitu bahwa evaluasi yang baik adalah evaluasi yang memberikan dampak positif pada perkembangan pelaksanaan suatu program[3].

\section{Tata kelola TI (IT Governance)}

Tata kelola IT adalah spesifikasian hak keputusan dan kerangka akuntabilitas untuk mengarahkan perilaku yang diinginkan dalam penggunaan TI[1]. Tata kelola TI tidak sekedar tentang pembuatan keputusan spesifik, tetapi lebih pada penentuan siapa yang secara sistematis membuat dan berkontribusi pada keputusan tersebut.

\section{COBIT}

COBIT (Control Objective for Information \& Related Technology) merupakan sekumpulan dokumentasi dan panduan untuk mengimplementasikan tata kelola TI, kerangka kerja yang membantu auditor, manajemen, dan pengguna (user) untuk menjembatani pemisah (gap) antara risiko bisnis, kebutuhan kontrol, dan permasalahan-permasalahan teknis[3].

\section{APO07 - Manage Human Resources}

Proses manage human resources berfokus dalam memastikan penempatan, penataan, keputusan, dan keterampilan sumber daya manusia yang optimal[5]. Hal ini termasuk mengkomunikasikan peran dan tanggung jawab, rencana pembelajaran dan pengembangan, dan ekspektasi kinerja yang didukung oleh staf-staf/yang kompeten[8]. Dalam proses ini mengandung beberapa praktek manajemen (management practices) yang meliputi: 
1. APO07.01 (Maintain adequate and approriate staffing) Mengevaluasi kebutuhan kepegawaian secara teratur

2. APO07.02 (Identify key IT personnel) Mengidentifikasi personil kunci TI dan meminimalkan ketergantungan pada satu individu saja

3. APO07.03 (Maintain the skills and competencies of personel) Secara teratur mendefinisikan dan mengelola ketrampilan dan kompetensi yang dibutuhkan oleh personil.

4. APO07.04 (Evaluate employee job performance) Lakukan evaluasi kinerja secara tepat waktu dan teratur terhadap tujuan in- dividu yang berasal dari apa yang ingin dicapai oleh perusahaan.

5. APO07.05 (Plan and track the usage of IT and business human resource) Memahami dan menelusuri kebutuhan bisnis saat ini dan masa depan serta sumber daya manusia TI dengan tanggung jawab untuk TI perusahaan.

6. APO07.06 (Manage contract staff) Pastikan bahwa konsultan dan tenaga kerja kontrak yang mendukung operasional perusahaan memiliki

\section{Capability Level}

Capability Level merupakan sebuah model untuk menggambarkan bagaimana setiap proses berjalan dalam sebuah organisasi atau perusahaan. indikator kapabilitas adalah kemampuan dalam meraih tingkat kapanilitas yang yang ditingkatkan oleh atribut proses[4].

\section{METODE PENELITIAN}

\section{Tahap Perencanaan}

Pada tahap perencanaan ini merupakan tahap awal dari penelitian. dalam tahap perencanaan ini terdapat beberapa kegiatan yang harus dilakukan diantaranya menentukan masalah, menentukan tujuan, dan menentukan data yang dibutuhkan.

\section{Tahap Pengumpulan Data}

dilakukan yaitu

Pada tahap ini ada beberapa tahapan yang perlu

1. Studi pustaka

Peneliti mengumpulkan data dengan cara mencari sumber untuk mendapatkan teori yang digunakan untuk mendukung penelitian yang dilakukan baik dari buku, jurnal, paper maupun e-book dan penelitian terdahulu serta literatur - literatur yang sesuai dan mendukung.

2. Wawancara

Wawancara dilakukan kepada staff pengelola teknologi informasi Kepala memiliki tugas pokok yaitu bertanggung jawab penuh terhadap seluruh proses yang ada dan tata kelola Teknologi Informasi dan Pangkalan Data (PTIPD) yaitu Benny Sukma Negara.

\section{Observasi}

Pada tahap ini penulis akan melakukan survei langsung dan melakukan magang selama dua bulan di PTIPD untuk melihat dan mengamati Sistem yang sedang berjalan, proses sistem, permasalahan yang pernah dialami dan bagaimana solusi yang diinginkan ole pihak PTIPD Uin Suska Riau.

\section{Kuesioner}

Kuisioner merupakan teknik pengumpulan data yang dilakukan dengan cara memberikan seperangkat pertanyaan kepada responden untuk dijawab. Data yang diperoleh dari hasil penyebaran kuesioner ini adalah data primer, yaitu data yang berasal langsung dari objek penelitian yang digunakan untuk menganalisis Kapabilitas Level (Capability Level) kinerja sistem informasi PTIPD

\section{Tahap Pengolahan dan Analisis Data}

Setelah melakukan proses pengumpulan data maka dihasilkan data dihasilkan data primer dan data skunder. Memberikan penjelasan mengenai hasil pengukuran yang telah dilakukan dalam bentuk grafik dan tabel dengan disertai penjelasan.Pengukurran capability level dilakukan berdasarkan jawaban responden pada kuesioner yang di sebarkan. Penilaian capability level terbagi menjadi level-level sebagai berikut:

1. Incomplete Process - level 0 Merupakan proses yang tidak lengkap, dimana proses ini hanya terdapat sedikit sekali bukti atau bahkan tidak memiliki bukti sama sekali dalam hal pencapaian dari tujuan proses.

2. Performed Process - level 1 Merupakan proses yang dijalankan. Proses yang dilakukan sudah mencapai tujuan.

3. Managed Process - level 2 Proses yang sudah mencapai tujuan dimplementasikan dengan lebih teratur, dijalankan, dikontrol, dan dikelola dengan tepat.

4. Established Process - level 3 Proses diimplementasikan secara teratur yang selanjutnya sudah berhasil ditetapkan dan sudah mencapai hasil yang diharapkan.

5. Predictable process - level 4 Proses ini dapat memprediksi. Proses yang berjalan dioperasikan dengan batasan yang telah ditentukan agar mendapatkan hasil yang sesuai dengan harapan.

6. Optimising process - level 5 Proses ini merupakan proses optimasi dimana proses yang telah berjalan dilakukan peningkatan berkelanjutan sebagai usaha pemenuhan baik dimasa sekarang maupun dimasa depan dari tujuan bisnis. 
7. Membuat Hasil Rekomendasi Setelah proses pengumpulan data, pengolahan dan analisa dilakukan, selanjutnya membuat rekomendasi berdasarkan pada tingkat kapabilitas yang dicapai, dan memberikan sebuah solusi untuk pemecahan permasalahan terkait IRAISE pada PTIPD.

\section{Rekomendasi}

Setelah proses pengumpulan data, pengolahan dan analisa dilakukan, selanjutnya membuat rekomendasi berdasarkan pada tingkat kapabilitas yang dicapai, dan memberikan sebuah solusi untuk pemecahan permasalahan terkait IRAISE pada PTIPD.

\section{HASIL DAN PEMBAHASAN}

\section{Analisa PTIPD Saat Ini}

PTIPD Uin Suska Riau merupakan pusat pengembangan dan pelayanan teknologi informasi untuk seluruh civitas akademika UIN Suska Riau. Untuk dapat menjalankan tugas-tugasnya dengan baik, maka seharusnya didukung oleh administrasi yang baik pula diantaranya pengelolaan Integrated Academic Information System (IRAISE). PTIPD Uin Sultan Syarif Kasim Riau saat ini memiliki 10 orang pegawai tetap Pada setiap divisi memiliki tugas yang tersambung pada sebuah wadah pelayanan yang disebut Customer Care Centre (C3). Sumber daya manusia yang ada di PTIPD saat ini Dalam proses pengelolaan layanan TI yang dilakukan terdapat beberapa aktor yang terlibat dalam penanganan, pemenuhan permintaan, pengelolaan akses, pemantauan status layanan, hingga penentuan problem layanan ditunjukkan pada tabel berikut

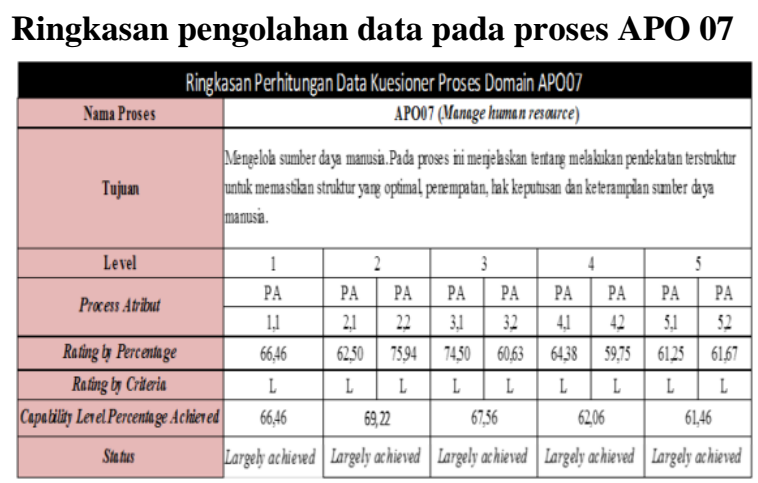

Gambar 1. Ringkasan perhitungan kuisioner
Hasil pengukuran pada proses operasional dan penggunaan IRAISE C3 pada PTIPD yang dilakukan untuk level 1 sampai dengan level 5 dengan menggunakan COBIT APO07, maka didapatkan hasil sebagai berikut:

1. Level 1 memiliki ketercapaian sebesar $66,46 \%$ yang berarti skala ketercapaian diposisi Largely Achieved (L).

2. Level 2 memiliki ketercapaian sebesar $69.22 \%$ yang berarti skala ketercapaian diposisi Largely Achieved (L).

3. Level 3 memiliki ketercapaian sebesar $67.56 \%$ yang berarti skala ketercapaian di posisi Largely Achieved (L).

4. Level 4 memiliki ketercapaian sebesar $62.06 \%$ yang berarti skala ketercapaian diposisi Largely Achieved (L).

5. Level 5 memiliki ketercapaian sebesar $61.46 \%$ yang berarti skala ketercapaian diposisi Largely Achieved (L).

Hal ini menunjukkan bahwa pengelolaan dilaksanakan sebagian besar. Kriteria secara garis besar sudah tercapai, dimana telah terdapat fakta atau bukti atas pendekatan sistematis dan pencapaian yang signifikan atas kriteria tersebut, meski masih ada beberapa kelemahan. Organisasi dikatakan mencapai level kapabilitas tertentu bila atribut pada level tersebut bernilai "fully achieved (F)" atau "largely achieved (L)" dan nilai atribut untuk seluruh level Kapabilitas di bawahnya bernilai "Largely achieved (L)". Oleh sebab itu, maka proses operasional dan penggunaan IRAISE C3 pada PTIPD uin suska riau telah mencapai tingkat kapabilitas pada level 3 (Largely achieved). dikarenakan nilai yang di dapat pada PTIPD dan terdapatnya kegiatan yang dipantau dan disesuaikan oleh pegawai lama yang memberikan pengetahuan dan prosedur Iraise kepada pegawai baru secara berskala namun tidak terjadwalkan. kegiatan yang dilakukan hanya disaat jam istirahat dilakukan. hal ini berarti bahwa proses yang dilakukan sebelumnya telah dikelola (direncanakan, dipantau dan disesuaikan) dan produk kerjanya telah didirikan, dikendalikan dan dipelihara.

Berikut ini hasil pencapaian pengelolaan pada proses domain APO07 


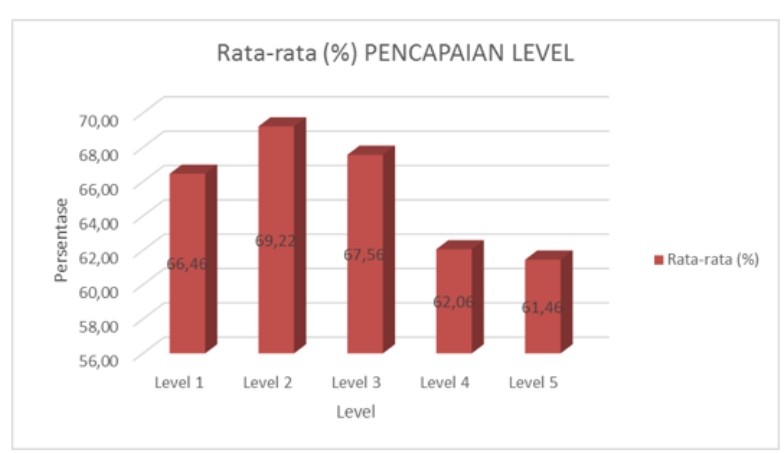

Gambar 2. Pencapaian level

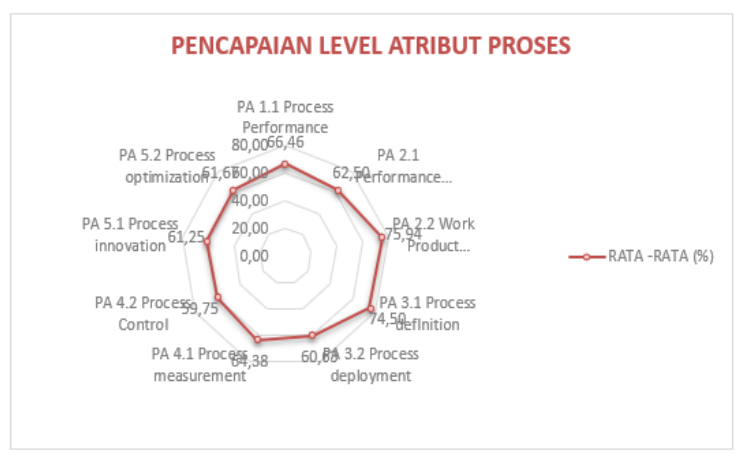

Gambar 3. Pencapaian level atribut proses

\section{Rekomendasi}

Rekomendasi menjelaskan solusi yang bisa diterapkan dengan melihat hasil rating nilai pada tiaptiap atribut proses yang sudah dinilai pada level satu hingga level yang akan dicapai. Berikut ini uraian rekomendasi perbaikan dari setiap atribut proses tersebut.

Tabel 1. Rekomendasi Proses Pengelaolaan Sumber Daya Manusia TI

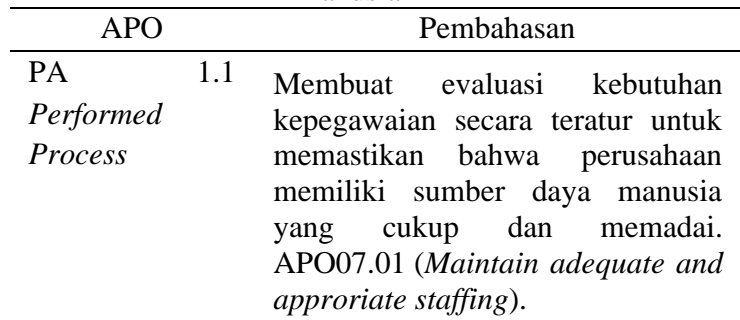

PA Level 3.1 Mengumpulkan dan menganalisa (Established data menengenai kegiatan proses Process) operasion al dan penggunaan IRAISE C3 pada P TIPD sebagai dasar dari perbaikan terus menerus.

PA Level 3.2 Mendefenisikan tujuan Process pengukuran terkait kegiatan proses Deploymen operasional dan penggunaan
IRAISE C3 pada PTIPD s esuai dengan kebutuhan informasi.

PA $\quad 5.1$ mengidentifikasi strategi secara Optimizing baku implementasi pengelolaan Process operasional dan penggunaan iraise

\section{KESIMPULAN}

Berikut adalah kesimpulan dari penelitian yang telah dilakukan:

Pencapaian level 1 memiliki ketercapaian sebesar $66.46 \%$ yang berarti skala ketercapaian diposisi Largely Achieved (L). Level 2 memiliki. ketercapaian sebesar $69.22 \%$ dan level 3 memiliki ketercapaian sebesar $67.56 \%$ yang berarti skala ketercapaian keduanya diposisi Largely Achieved (L). Level 4 memiliki ketercapaian sebesar $62.06 \%$ dan Level 5 memiliki ketercapaian sebesar $61.46 \%$ yang berarti skala ketercapaian diposisi Largely Achieved (L). Hal ini menunjukkan bahwa pengelolaan dilaksanakan sebagian kecil. Kriteria telah tercapai sebagian, telah terdapat beberapa fakta atau bukti mengenai kriteria yang telah dicapai.

Rekomendasi perbaikan yang dapat dilakukan oleh PTIPD Uin Suska Riau proses APO07 Sumber daya Manusia TI dalam mencapai target tingkat kapabilitas di level 1 adalah penjadwalan kegiatan pelatihan, sharing informasi dan pemenuhan kompetensi dilakukan dengan mendorong adanya pelatihan dan pendidikan sertifikasi serta melakukan internal dan eksternal rekrutmen. Kemudian kegiatan penjadwalan training secara reguler kepada SDM yang baru agar dapat menyesuaikan work product dengan kebutuhan, selain itu untuk staff senior agar diberikan dokumentasi evaluasi yang memadai. Kegiatan audit terhadap aktifitas staffnya juga harus dilakukan agar sesuai dengan standar proses dan dapat di evaluasi kedepannya. Selanjutnya penambahan staff IT yang bertanggung jawab di bidang IRAISE dengan masingmasing jobdesk agar kinerja staff lebih terstruktur.

Penggunaan TI dalam mencapai target tingkat kapabilitas di level 3 dengan membuat SOP pengelolaan sistem informasi di PTIPD yang di dokumentasikan dalam bentuk cetak ataupun elektronik. Kemudian memberikan materi training kepada SDM yang baru agar dapat menyesuaikan work product dengan kebutuhan.

\section{SARAN}

Berikut ini merupakan saran yang dapat diberikan dalam penelitian di PTIPD dan digunakan sebagai pengembangan selanjutnya: 
1. Disarankan untuk meningkatkan level kapabilitas 3 (Established Process) agar menjadi referensi lainnya.

2. Supaya rekomendasi perbaikan dapat berjalan dengan baik, langkah pertama yang harus diambil adalah mengedukasi Sumber Daya Manusia secara bertahap dalam memahami standar proses yang ada. Kemudian, melakukan pengamatan terhadap SOP (Standar Operasional Produk) yang mengatur seluruh kegiatan PTIPD agar kedepannya dokumen dapat menjadi bekal ke level 3.

3. Perlu adanya audit atau evaluasi secara berkala dengan target strategi perkembangan setiap tahunnya, dari sisi manajemen sumber daya manusia, dari prasarana operasional dan penggunaan IRAISE.

\section{REFERENCES}

[1] Adikara, F., dan Pambudi, A. (2012). Analisis kebutuhan stakeholder dalam rangka mengembangkan model tata kelola teknologi informasi dengan kerangka kerja cobit-5 pada perguruan tinggi. Prosiding KNTI.

[2] Alsri, W. (2017). Evaluasi sdm sistem informasi akademik poltekkes kemenkes padang menggunakan framework cobit 5. JURNAL
RESTI (Rekayasa Sistem Dan Teknologi Informasi), 1(2), 146-152.

[3] Audit, I. S., Association, C., dan Isaca. (2012). Cobit 5: Implementation.ISACA.

[4] Hakim, A., Saragih, H., dan Suharto, A.(2014). Evaluasi tata kelolateknologi informasi dengan framwork cobit. 5 di kementerian esdm. Jurnal Sistem Informasi, 10(2), 108-117.

[5] Novita, R., Nugroho, E., dan Sumaryono, S.(2014). Penilaian tingkat capability tata kelola ti pada aspek manajeman sumber daya manusia. SEMNASTEKNOMEDIA ONLINE, 2(1), 2-07.

[6] Permata, U., dan Dedi, D. (2016). Audit tata kelola teknologi informasi (emis) menggunakan framework cobit 5 pt. tdm bandar lampung. Dalam (Vol. 10, hal. 1-6).

[7] Pragita, C., Firdaus, Y., dan Perdana, E. (2014). Analisis audit sistem informasi pada domain apo (align, plan, and organise) manage quality dengan menggunakan cobit framework (studi kasus: Direktorat sistem informasi universitas telkom). eProceedings of Engineering, 1(1).

[8] Umar, H. (2002). Evaluasi kinerja perusahaan. Gramedia Pustaka Utama. 